\title{
USING SATELLITE IMAGES FOR WIRELESS NETWORK PLANING IN BAKU CITY
}

\author{
Magsad Gojamanov, Jamal Ismayilov \\ Baku State University \\ 23, Z. Khalilov str., Baku, Azerbaijan \\ mgodja@yandex.ru \\ jamal_ism@yahoo.com
}

KEY WORDS: Space, mobile communication, digital map, GPS, clutter

\begin{abstract}
:
It is a well known fact that the Information-Telecommunication and Space research technologies are the fields getting much more benefits from the achievements of the scientific and technical progress. In many cases, these areas supporting each other have improved the conditions for their further development. For instance, the intensive development in the field of the mobile communication has caused the rapid progress of the Space research technologies and vice versa.Today it is impossible to solve one of the most important tasks of the mobile communication as Radio Frecance planning without the 2D and 3D digital maps. The compiling of such maps is much more efficient by means of the space images. Because the quality of the space images has been improved and developed, especially at the both spectral and spatial resolution points. It has been possible to to use 8 Band images with the spatial resolution of $50 \mathrm{sm}$
\end{abstract}

At present, in relation to the function $3 \mathrm{G}$ of mobile communications one of the main issues facing mobile operator companies is a high-precision 3D digital maps. It should be noted that the number of mobile phone users in the Republic of Azerbaijan went forward other Community of Independent States Countries.

Of course, using of aerial images for 3D mapping would be optimal. However, depending on a number of technical and administrative problems aerial photography cannot be used. Therefore, the experience of many countries shows that it will be more effective to use the space images with the higher resolution for these issues.|

Concerning the fact that the mobile communication within the city of Baku has included 3G function there were ordered stereo images wih the spatial resolution of $50 \mathrm{~cm}$ for the $150 \mathrm{sq} . \mathrm{km}$ territory occupying the central part of the city in order to compile 3D digital maps. The images collected from the WorldView-2 satellite are 4-Band Bundle(Pan+MS1) stereo images. Such kind of imagery enable to automatically classificate some required clutter classes.Meanwhile, there were created 12 GPS points in the territory and there have been held some appropriate observations in these points for the geodesic reference of the space images in the territory. Moreover, it would like to mention that there have been constructed 37 permanently acting GPS stations in the territory of Azerbaijan at present. It significantly facilitates the process of the geodesic reference of the space images in order to accomplish such kind of mentioned projects.

The processing of the collected space images was accomplished by means of Erdas LPS 10 program. In the first stage there was created the main component of the 3D maps- Digital Elevevation Model.In this model the following clutter classes are presented:

Open; Open areas in urban; Airport, Sea, Inland water; Forest; Parks in urban; Semi Open Area; Open Wet Area; Urban / Urban Mean; Dense urban, Villages, Industrial / Commercial, Residential / Suburban; Dense residential / Suburban; Block of BUILDINGS; Dense Urban High; Buildings, Urban Mixed, Mixed dense urban

It is well-known that beginning from the end of the 20th century mobile communication has been widely extending the world. Mobile operator companies ding all over hold a lot of projects concerning researching and removal of all the sources obstructing the transmission of communication signals with high accuracy. It is very important to obtain clutter information in this context. Clutter information is the information about the technogenic and natural objects that are able to reduce the radio waves spreading. From the initial periods of mobile communication emergence this information was received from the existing topographic maps. However, the swift development of cosmic images and Remote Sensing moved to the back side the use of topographic maps for such purposes nowadays. Because the Radio Frecance planning with cosmic methods provides you with access to more accurate clutter information. Meanwhile, the information obtained by means of ground methods causes the high reliability of clutter classes and features controlling purposes.

One of the crucial indicators of the quality of mobile communications when it is established is the little size of infrastructure expenses and the high level of broadcasting services. It is possible to achieve it by the optimal placement of communication antennas in the region. At the same time, the right selection of the places for antennas needs the collection of detailed clutter information.

The expansion of the coverage area of WIMAX, 3G, 4G, LTE communication networks depends on the existence of high resolution maps or 3D clutter information.

The collection of the clutter information for rural areas is accomplished by means of supervised classification method. However, in urban territories it is suggested to do this work manually, e.g. image interpretation. Because in this case it is possible to more efficiently differ objects from one another taking into account the morphology of the urban territory as well as the density of buildings.

For accomplishment of Radio Frecance planning project in Baku city there were ordered multispectral stereo images from WorldView-2 satellite for 150 sq. $\mathrm{km}$. territory. 
Moreover, we would like to mention as there have been realized radical restructuring projects in Baku for last 10 years, the new high multistoried buildings have found more precise mapping and their resolution have been realized much more exactly and easier in comparison with old objects.

The creation of clutter information database begins with the orthorectification process of the first cosmic images. For this purpose it is required to determine the geodesic closure of the images on the surface, e.g. the appropriate GPS points in the territory. In this case the GPS points have to be equally distributed in the territory. Generally, it is sufficient to choose 7-10 GPS points for $100 \mathrm{sq}$. km. territory. Furthermore, the places of the points are chosen by viewing the cosmic images. Later, by observing satellite measurements in the same points, the plan and altitude coordinates concerning WGS-84 ellipsoid are determined with $0.1 \mathrm{~m}$ accuracy. As the normal altitudes in Baltic Sea system are displayed in the map of Azerbaijan, there have been shift from GPS altitude measurements to this system.

There is shown the placement scheme of GPS points concerning Baku city project in the figure 1 .

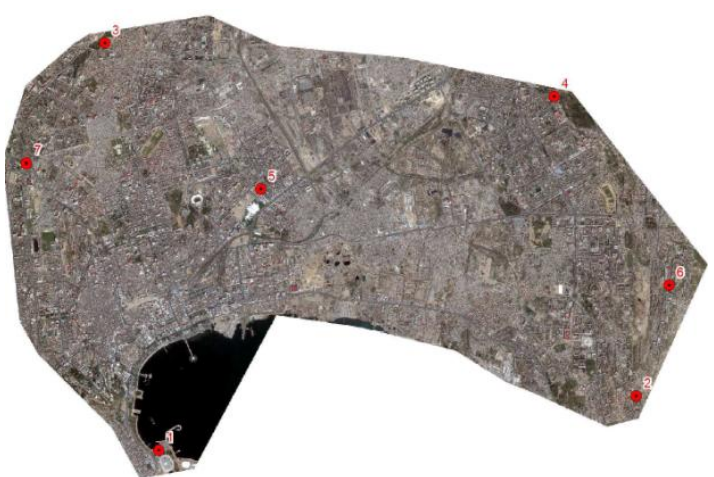

Figure 1. The placement scheme of GPS points

\section{Digital Terrain Model Extraction}

In the second stage there was created the digital model of the relief of the territory. Digital Elevation Model (DEM) is inseparable part of Geospace information and it is broadly used in the creation of clutter information. Because, DEM is used not only for getting information about the relief (altitude) of the investigated territory, but also in orthotransformation of cosmic images. Within the framework of the project the DEM model of Baku city was created by means of Ortho-Ready Stereo imagery taken from WorldView-2 satellite. In this case there were used RPC model in ERDAS LPS program environment and stereo block files for DEM extraction process. In the figure 2 there is shown the DEM for some part of Baku city.

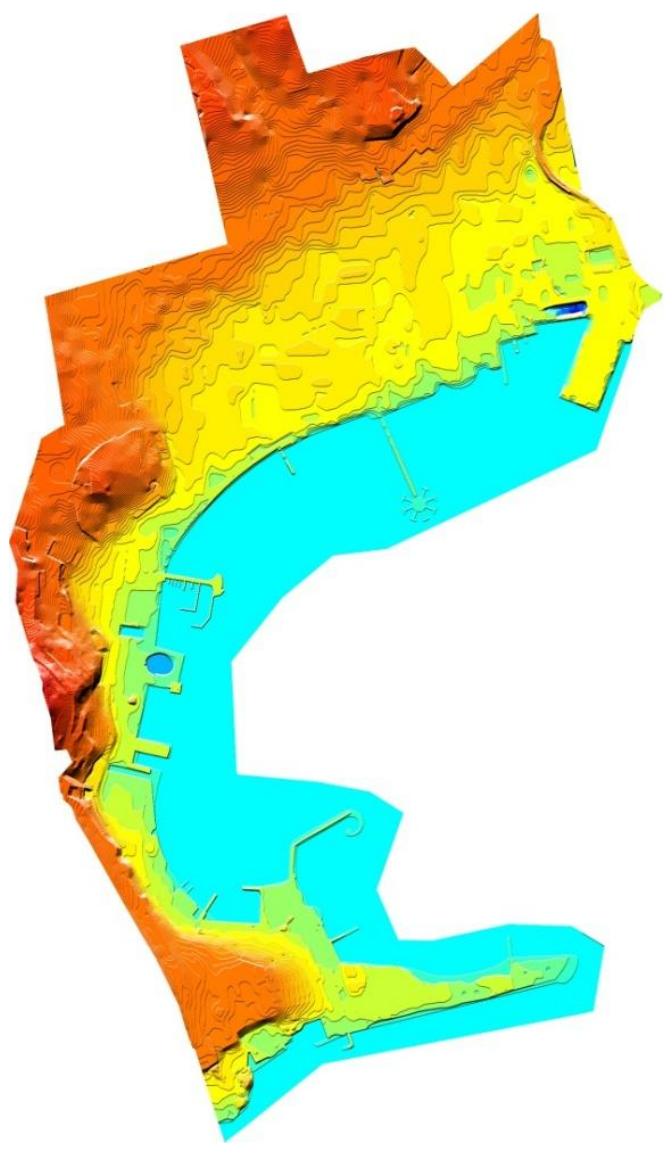

Figure 2. DEM image of Baku city

\section{D Feature Extraction}

As it was mentioned above, for urban territories, especially in small places it is suggested to choose clutter classes by means of manual method. There are different software for this purpose, we have used LPS stereo method for Baku city project. The borders of buildings and constructions, greenness objects, Caspian Sea and internal open water basins, the shoreline circuit of Caspian sea and their altitude indicators are accepted as the main quantitative indicators of clutter information. Meanwhile, vector information model consists of 9 classes: the outlines of buildings, various road and street types, railways, the shoreline of sea, channels, the airport and flora cover outlines (figure 3). This information has been gathered in GIS map layers, and it enables you to analyze them separately.

The construction of high-rise buildings in Baku city has gained momentum in recent years, a number of 16-22 storey buildings have been built. By means of some appropriate software there have been received information about the quantity and general height of the schools in these buildings. Then this information was grouped and was made suitable for visualization of the general view of the city (figure 4). 


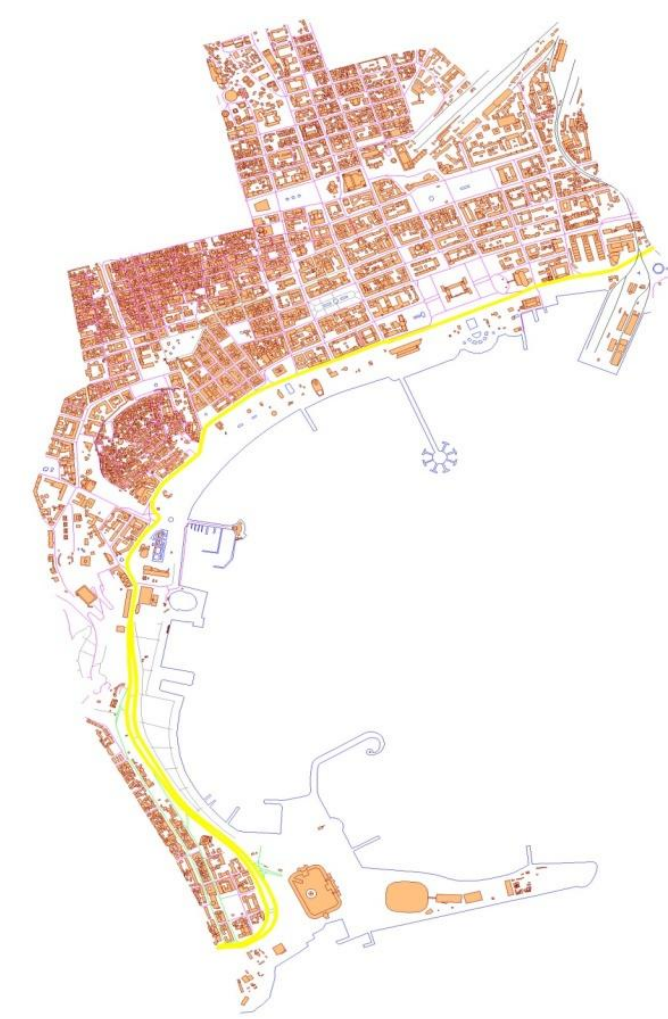

Figure 3. The selection of clutter classes.

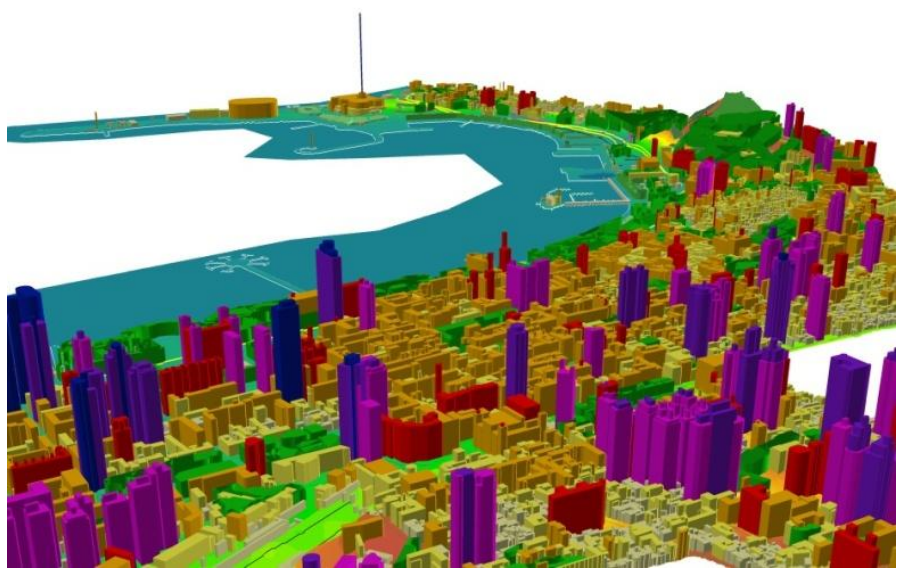

Figure 4. The visual view of the buildings in Baku city.

After entire completion of the vectorization process the clutter classes were identified (table 1) and clutter model was created (figure 5). Clutter model consists of 20 classes and reflects 10 classes of construction areas, 3 classes of water bodies, 7 classes of landscape and vegetation cover.

\begin{tabular}{|c|c|c|}
\hline № & Class name & Description \\
\hline 1. & Open & Open area with little or no vegetation \\
\hline 2. & $\begin{array}{l}\text { Open_areas_in_ur } \\
\text { ban }\end{array}$ & $\begin{array}{l}\text { Small open land area with no vegetation } \\
\text { surrounded by mean urban, dense urban, } \\
\text { or residential. }\end{array}$ \\
\hline 3. & Airport & Territory of airport \\
\hline 4. & Sea & Ocean and Sea \\
\hline 5. & Inland water & $\begin{array}{l}\text { Rivers and canals with width }>10 \mathrm{~m} \text {. } \\
\text { Lakes, water body }\end{array}$ \\
\hline 6. & Forest & $\begin{array}{l}\text { Forested lands with heights }>20 \mathrm{~m} \text {. No } \\
\text { distinction is made between deciduous } \\
\text { and coniferous }\end{array}$ \\
\hline 7. & Parks_in_urban & $\begin{array}{l}\text { Vegetation land in urban environment } \\
\text { (parks, cemeteries, recreation zones) }\end{array}$ \\
\hline 8. & Semi Open Area & $\begin{array}{l}\text { Area with mixed low vegetation, bushes } \\
\text { and few trees. }\end{array}$ \\
\hline 9. & Open Wet Area & Marshlands, rice fields, swamps \\
\hline 10. & $\begin{array}{l}\text { Urban/Mean } \\
\text { urban }\end{array}$ & $\begin{array}{l}\text { Urban apartment blocks with heights 3-7 } \\
\text { floors. The streets structure is regular. }\end{array}$ \\
\hline 11. & Dense_urban & $\begin{array}{l}\text { Dense urban apartment blocks with } \\
\text { heights 3-7 floors. }\end{array}$ \\
\hline 12. & Villages & $\begin{array}{l}\text { Built-up area in rural surrounding } \\
\text { (villages, rest homes, gardens). }\end{array}$ \\
\hline 13. & $\begin{array}{l}\text { Industrial/ } \\
\text { commercial }\end{array}$ & $\begin{array}{l}\text { Industrial and commercial buildings with } \\
\text { large footprints (industrial zones, } \\
\text { storehouses, garages, business shopping } \\
\text { centers, shopping malls). }\end{array}$ \\
\hline 14. & $\begin{array}{l}\text { Residential/Subur } \\
\text { ban }\end{array}$ & $\begin{array}{l}\text { Individual houses and gardens in urban } \\
\text { and suburban environment. The streets } \\
\text { structure is regular. Average height of } \\
\text { buildings is } 1-3 \text { floors }\end{array}$ \\
\hline 15. & $\begin{array}{l}\text { Dense_residential } \\
\text { /suburban }\end{array}$ & $\begin{array}{l}\text { Dense built-up area with individual } \\
\text { houses in urban and suburban } \\
\text { environment. The streets structure is } \\
\text { irregular. Average height of buildings is } \\
1-3 \text { floors }\end{array}$ \\
\hline 16. & $\begin{array}{l}\text { Block of } \\
\text { buildings }\end{array}$ & $\begin{array}{l}\text { Urban apartment blocks with heights }>7 \\
\text { floors. The streets structure is } \\
\text { regular.(Usually considered as micro } \\
\text { districts with regular buildings) }\end{array}$ \\
\hline 17. & $\begin{array}{l}\text { Dense Urban } \\
\text { High }\end{array}$ & $\begin{array}{l}\text { Dense built-up area with building's } \\
\text { heights }>7 \text { floors (without stand-alone } \\
\text { buildings). Financial and business } \\
\text { districts. }\end{array}$ \\
\hline 18. & Buildings & $\begin{array}{l}\text { Stand-alone high towers or skyscrapers } \\
\text { higher than } 7 \text { floors. }\end{array}$ \\
\hline 19. & Mixed urban & $\begin{array}{l}\text { Irregular buildings without vegetation that } \\
\text { include } 1-6 \text { floors buildings from different } \\
\text { classes. }\end{array}$ \\
\hline 20. & $\begin{array}{l}\text { Mixed dense } \\
\text { urban }\end{array}$ & $\begin{array}{l}\text { Dense irregular buildings without } \\
\text { vegetation that include 1-6 floors } \\
\text { buildings from different classes. }\end{array}$ \\
\hline
\end{tabular}


International Archives of the Photogrammetry, Remote Sensing and Spatial Information Sciences, Volume XL-1/W1, ISPRS Hannover Workshop 2013, 21 - 24 May 2013, Hannover, Germany

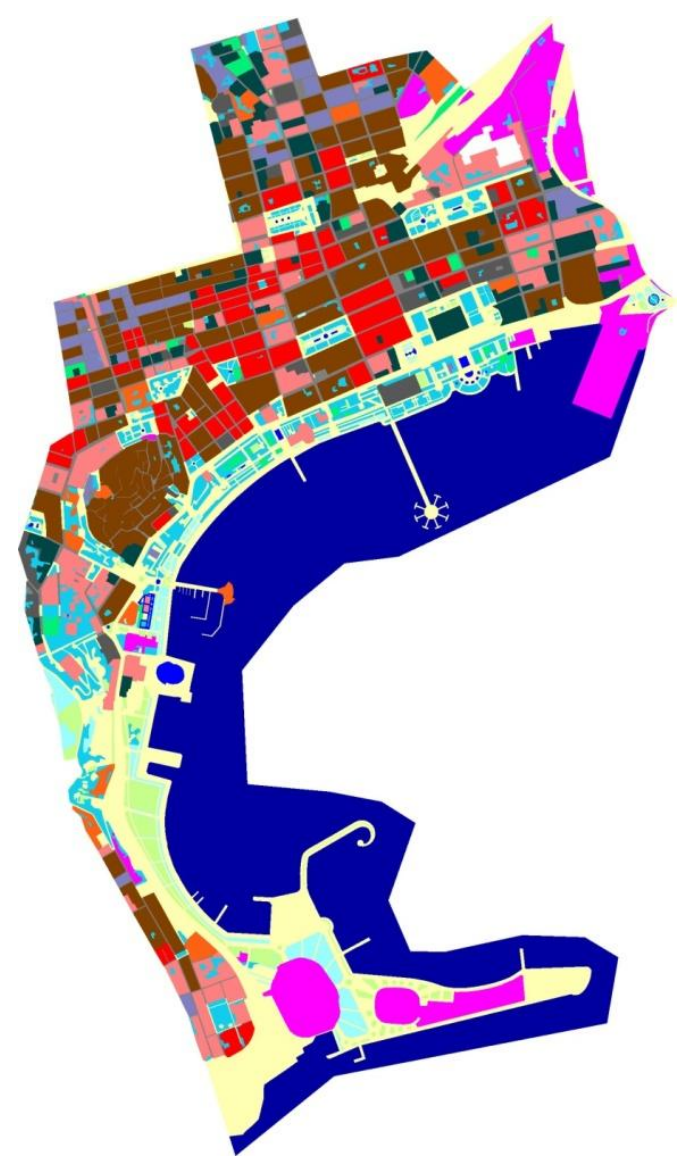

Figure 5. Clutter map scheme in Baku city

\section{CONCLUSIONS}

The following conclusions and recommendations can be made on the project concerning the development of mobile communication in Baku city:

1. Cosmic images enable to collect clutter information much more accurately and comprehensively in Radio Frecance planning project.

2. It is much more effective and recommended to carry out manual clutter data collection in urban areas.

3.Tested in Baku city the technological scheme of Radio Frecance planning and classification of clutter classes can be used in other areas to carry out analogical affairs.

\section{REFERENCES}

1. The Application of Land Use / Land Cover (Clutter) Data to Wireless Communication System Design. Harry Anderson, Ted Hicks, Jody Kirtner EDX Wireless, LLC Eugene. Oregon USA, EDX Wireless, 2008

2. Land Use Classification Xiaoning Gong, Lars Gunnar Marklund and Sachiko Tsuji, FAO, $14^{\text {th }}$ Meeting of the London Group on Environmental Accounting. Canberra, 27 30 April, 2009

3. Land Use / Cover Classification Techniques Using Optical Remotely Sensed Data in Landscape Planning. The book edited by Onur Şatır and Süha Berberoğlu.- June 13, 2012 